\title{
Better Nutrition for the Poor through Informal Markets
}

In the fight against undernutrition, policymakers are seeking to use markets to increase access to nutrient-rich foods. Yet ensuring food reaches those most affected by undernutrition requires shaping the markets and businesses from which they source food. Poor people in rural and urban areas tend to buy food - including the foods most important for nutrition - not from large businesses, but from small enterprises and informal markets. To make a difference in these markets, development actors have to work differently. Experiences of past programmes highlight the importance of building the capacity of informal businesses, capitalising on their flexibility and building consumer trust. Better data, innovative research and experimentation need to be the priorities for policymakers.

There is a global crisis of undernutrition, which contributes to nearly one in five of all child deaths. Deficiencies in essential micronutrients such as iron and vitamin $A$ are one of the most common types of undernutrition. Improving diets is a key part of the solution. In tackling the global crisis of undernutrition and micronutrient deficiencies, donors and policymakers are increasingly looking to market mechanisms to deliver micronutrients to undernourished people. Market-based approaches are diverse, ranging from the development of low-cost fortified products to mandatory fortification regulations to building markets for nutrient-rich crops. Yet all of these approaches face a challenge in ensuring that nutrient-rich products reach the poor, who are disproportionately affected by undernutrition. In most countries, poor people - both in urban and rural areas - do not buy food from large businesses, but from a plethora of micro-enterprises functioning in the informal sector.

The informal sector is a major gap for food-based nutrition policy. While current approaches targeting formal markets have seen limited successes, they ultimately cannot address the undernutrition problem because they

\section{What is the informal food sector?}

\begin{abstract}
The informal food sector covers an extremely diverse range of enterprises, which operate across food value chains in farming, trade and distribution, processing, and retail. While many of these are very small, some serve large numbers of consumers. There are different levels of informality; some businesses have both formal and informal operations, while some are considered illegal national agencies but pay taxes to local government. Rarely are these activities captured in official statistics. Yet the informal sector makes up as much as half of economic activity in some countries, and it plays a crucial role in the food systems that serve the poor.
\end{abstract}

do not reach sufficient numbers of poor people. For example, Nigeria's and Tanzania's National Fortification programmes have made little progress in markets with a strong informal sector presence. Policymakers and donor agencies need new strategies for working with the informal sector to improve nutritional quality.

The poor buy food from informal markets

A large portion of business activities in food markets in low and middle-income countries occur in the informal sector, particularly for fresh foods, such as
"In tackling the global crisis of undernutrition and micronutrient deficiencies, donors and policymakers are increasingly looking to market mechanisms to deliver micronutrients to undernourished people." 
fruits, vegetables, milk and meat (Figure 1). Even for staple foods such as maize, a major portion of trade and processing occurs informally. In Kenya, only 25 per cent of total maize sales were officially recorded by the customs agency in 2008.

Poor populations are especially likely to buy food from the informal sector. In Tanzania only 18 per cent of those in the bottom three wealth quintiles purchased packaged maize flour; the remainder often paid small-scale millers to process maize. Although several large manufacturers produce much of the vegetable oil in the country, only 46 per cent of the poor purchase these brands, while others appear to buy from the informal sector.

For certain products and in certain countries, very poor people do source from the formal sector. This often occurs for low-cost, imported foods that have no local equivalent (e.g. wheat flour), or essential products that cannot be produced locally (e.g. salt in landlocked countries). Yet, even when poor people buy centrally processed products, they often do so in very small quantities; the poorest 20 per cent of Tanzanians consume on average just $3 \mathrm{~g}$ of centrally produced wheat flour per day.

\section{Recognising the informal sector in policy}

The problem is that current policy approaches to food and nutrition face a major gap when dealing with the informal sector, and this is severely limiting their coverage. For example, while national fortification programmes in Tanzania and Nigeria achieved some success introducing micronutrient fortification for products made by large companies, they have been unable to cover informal sector products. Because the informal sector products are at a much lower cost, the poor are being steered towards eating the cheaper, unfortified products. Large companies, meanwhile, are not able to earn commercial returns selling fortified products to the poor.

Development actors need to realistically assess both formal and informal markets' potential for improving nutrition. Informal markets already contribute to the nutrition of the poor by making nutrient-rich foods available at low prices, and distributing food widely in contexts where infrastructure is poor. Yet
Figure 1 Market shares in the modern and traditional sectors for fresh fruit and vegetables.

Modern food value chain retail $\square$ Traditional food value chain retail

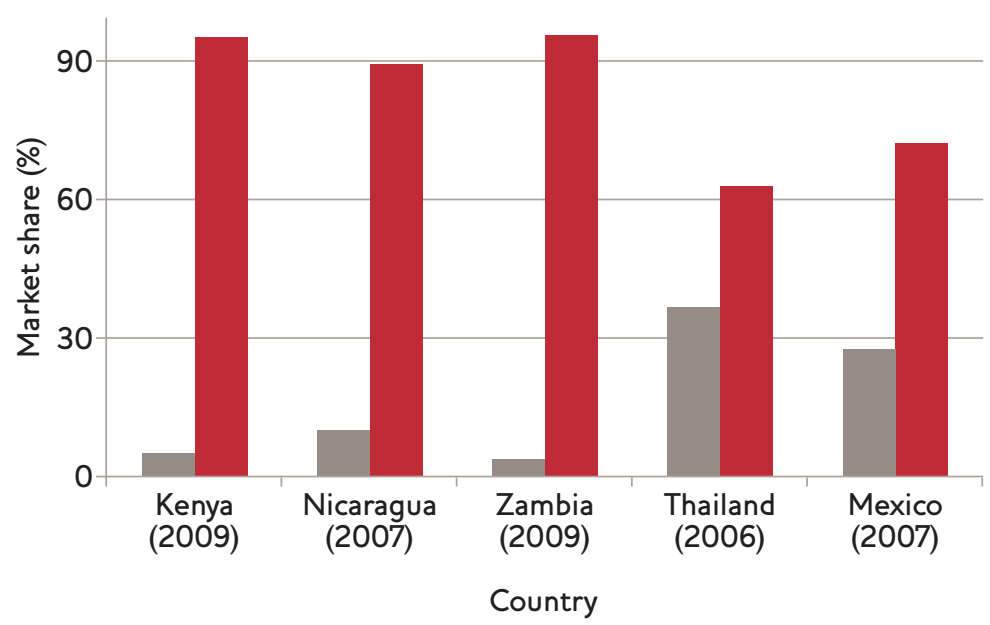

Source: Adapted from Gómez and Ricketts (2013)

informal markets are certainly not a panacea.

They can harbour food safety risks, and do not necessarily provide good nutritional quality. Many existing policies are based on the assumption that the informal sector will disappear, and be replaced by modernised value chains. However, evidence from African countries indicates that the poor will continue to rely on informal markets for the foreseeable future.

Regulating informal activities is notoriously difficult. Yet, development actors concerned with nutrition cannot afford to ignore them. Instead, they should develop innovative ways to improve the nutritional quality of the foods delivered by informal markets.

\section{Working with informal markets}

Policies should be designed to create market incentives for informal enterprises to deal in nutrient-rich foods, and to help them overcome the challenges they face. Small enterprises generally lack access to technology, finance and training to implement sophisticated upgrades such as fortification. Standard policy approaches, such as regulatory crackdowns on informal operators, can be counterproductive, pushing small enterprises further 'underground' and decreasing the quality and safety of products.

Meanwhile, conventional partnerships with donors and government do not work for the informal sector, since small enterprises are
"The informal

sector is a major gap for food-based nutrition policy. While current approaches targeting formal markets have seen limited successes, they ultimately cannot address the undernutrition problem because they do not reach sufficient numbers of poor people." 
numerous and widely scattered, and public agencies lack capacity to engage with them consistently. For example, one Tanzanian regulatory agency office had only two staff members with which to cover between 1,000 and 2,000 small maize millers. Those designing and implementing policies need to develop new, efficient approaches and strengthen their own capacity to engage with these markets. Although experience in nutrition policy is very limited, innovative methods are being developed in other areas, notably food safety.

Research on food safety suggests principles for programmes aiming to improve markets for nutrient-rich foods:

\section{- Identify areas where informal businesses have capacity to produce nutrient-dense products, especially those involving simple technology and processes (see examples below)}

\section{- Build on existing consumer knowledge.}

Behaviour change campaigns may be most effective when they target foods with special nutrition importance (e.g. complementary foods) and with which people are familiar. They should also target foods whose nutritional quality consumers can already evaluate (e.g. fresh fruits and vegetables, pulses, milk)

- Design training for informal businesses to achieve better nutritional quality. Training and business support must respond to the specific conditions and constraints they face. Businesses have a major incentive to improve quality: to attract and maintain a base of customers

\section{- Leverage relationships between businesses} and customers to improve information flows in the market. For example, programmes might collect and publicise consumer reviews through simple notice boards or through mobile phone-based platforms.

\section{How can programmes work with the informal sector?}

\section{Improved complementary foods in Ghana}

In the 1980s, the United Nations Children's Fund (UNICEF) and the Ghana Health Service introduced an improved complementary food known as Weanimix, which combined locally

\section{Lessons from research on food safety in informal markets}

Research conducted by the International Livestock Research Institute has assessed policy approaches for improving food safety in informal markets for meat and milk products. $A$ number of findings are contrary to assumptions often made by policymakers:

- Informal markets often do not necessarily entail greater food safety risks than formal markets, because of common consumer practices (for example, boiling milk)

- Stricter standards in formal value chains do not necessarily lead to better quality in the informal sector

- Harsh regulatory approaches (closing down informal vendors) can be counterproductive, actually reducing overall food safety for the poor.

The research has piloted alternative approaches, which have had positive impacts on food safety:

- Identifying and disseminating 'best practices' among informal businesses

- Providing training and facilitating access to simple, low-cost technologies

- Public awareness campaigns to strengthen consumers' existing abilities to make wise choices and minimise risks.

available ingredients. Originally promoted for small-scale processing, the product became popular and small enterprises began producing the product in urban areas. This has been a partial success, as only a minority of Weanimix products are nutritionally adequate. Nonetheless, the intervention successfully tapped into the strengths of the informal food sector, leading to rapid diffusion of a nutrition-sensitive technology and reaching large numbers of poor consumers. This success appears to result from the focus on a popular traditional food, use of simple technology and the provision of training and business skills to women entrepreneurs.

\section{Small-scale fortification in Tanzania}

One programme in Tanzania aimed to enable small enterprises to fortify their products, in line with the national fortification policy. It aimed to help the businesses to comply with government registration requirements, but this proved to be a major challenge. Only 15 maize mills were successfully registered, and none were able to begin fortification. The lesson is that working with the informal

\section{"Policies should be designed to create market incentives for informal enterprises to deal in nutrient- rich foods, and to help them overcome the challenges they face."}


sector needs longer-term investment to achieve change and requires donors and governments to cooperate to create a more supportive policy environment, by for example, making it easier to register small businesses.

\section{Informal retailers of micronutrient powders}

An alternative approach is to make use of the informal sector's distribution capacity to market centrally produced products. $A$ number of programmes, including trials in
Kenya and Ghana, are experimenting with distribution of micronutrient pouders (or 'sprinkles') to poor populations. This includes working with village-based entrepreneurs who sell the pouders (which are often imported) alongside their normal products. This approach requires that consumers are motivated to undertake fortification correctly in their homes, that regulation exists to facilitate home fortification and that regulators are able to monitor the quality of centrally produced powders.

\section{Policy recommendations}

Country-level experiences provide a starting point for how policy actors can work with informal markets to provide affordable, nutrient-rich foods. Yet the effectiveness of these approaches has yet to be proven. To make significant progress new programmes should be designed with a view to experimentation and learning. As shown in the Ghana case, informal markets have the potential for large-scale impacts when innovations are rapidly taken up by other enterprises. Yet new policy approaches require donors to invest for long-term impacts, to adapt in response to new information and to tolerate and learn from failures. Strengthening evidence and learning from other sectors are key priorities. Donor agencies and non-governmental organisations supporting business- and market-based nutrition programmes should:

- Rigorously investigate which products poor people eat and which value chains provide them. Where evidence is not available, they should fund studies.

- For products made in both the formal and informal sectors, nutrition programmes should work with the informal sector to reach the poorest people.

- Design interventions should be specifically tailored to the characteristics of informal markets. Regulatory and quality assurance approaches that work for large businesses are unlikely to work in the informal sector.

- Focus on approaches that use simple technology and training, and that capitalise on the flexibility of informal markets, existing consumer knowledge and trust.

- Donors should invest to improve the coverage and capacity of regulatory systems at the local level. They should lobby for supportive policies, and work closely with relevant ministries and other stakeholders. Donors should adopt a long-term perspective.

- Governments should create streamlined, low-cost processes that enable small enterprises to register and achieve a level of regulatory compliance. This will make them easier to identify, support and monitor.

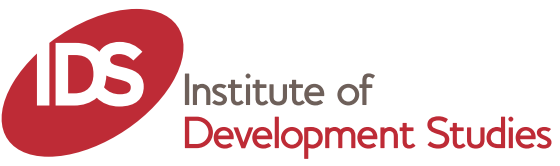

\section{NT/2 $7 \mathrm{MN}$ UKaid}

IDS Policy Briefings are published by the Institute of Development Studies and aim to provide high quality analysis and practical recommendations for policymakers on important development issues. To subscribe: www.ids.ac.uk/idspolicybriefings

Institute of Development Studies, Brighton BN1 9RE UK

T+44 (0) 1273606261 F + 44 (0) 1273621202 E ids@ids.ac.uk W www.ids.ac.uk

y twitter.com/IDS_UK \#idspolicy $\mathbf{f}$ facebook.com/idsuk

\section{Further reading}

Gómez, M.I. and Ricketts, K.D. (2013) 'Food Value Chain

Transformations in Developing

Countries: Selected Hypotheses

on Nutritional Implications',

Food Policy 42: 139-50

Grace, D. (2014) 'Food Safety in

Informal Markets', IFPRI 2020

Policy Consultation and Conference,

IFPRI: Addis Ababa, 15-17 May 2014

Robinson, E; Akinyele, I.O.;

Humphrey, J. and Henson, S.

(2014) Policy Options to Enhance

Markets for Nutrient-dense Foods

in Nigeria, Evidence Report 66,

Brighton: IDS

Robinson, E;: Temu, A.; Waized

B.; Ndyetabula, D.; Humphrey, J.

and Henson, S. (2014) Policy

Options to Enhance Markets for

Nutrient-dense Foods in Tanzania,

Evidence Report 90, Brighton: IDS

\section{Credits}

This IDS Policy Briefing was

written by Ewan Robinson and

John Humphrey. It was edited

by Vivienne Benson. It was

produced as part of the IDS

Reducing Hunger and

Undernutrition programme,

supported with UK aid from

the UK Department for

International Development.

The opinions expressed are

those of the authors and do not

necessarily reflect the views of

IDS or the UK government's

official policies.

Readers are encouraged to

quote and reproduce material

from the IDS Policy Briefing

series. In return, IDS requests due

acknowledgement and quotes

referenced as above.

AG Level 2 Output ID: 14

(C) Institute of Development Studies, 2015 ISSN 1479-974X 